\title{
Relating Molecular Morphology to Charge Mobility in Semicrystalline Conjugated Polymers
}

\author{
M. L. Jones, ${ }^{\dagger}$ D. M. Huang, ${ }^{\S}$ B. Chakrabarti, ${ }^{\ddagger}$ and C. Groves ${ }^{*} \dagger$ \\ ${ }^{\dagger}$ School of Engineering and Computing Sciences and ${ }^{\ddagger}$ Department of Mathematical Sciences, The University of Durham, South Road, \\ Durham DH1 3LE, U.K. \\ ${ }^{\S}$ Department of Chemistry, The University of Adelaide, Adelaide, SA 5005, Australia
}

Supporting Information

ABSTRACT: The molecular-level origins of the effects of annealing temperature and molecular weight on hole mobility in P3HT are elucidated using coarse-grained molecular dynamics, quantum chemical calculations, and kinetic Monte Carlo charge-transport simulations on a variety of realistic thinfilm morphologies. The zero-field hole mobility is shown to increase as the annealing temperature or average molecular weights of samples are increased, in accordance with experimental results. Crystal structure analysis shows that the annealing temperature dependence of the mobility can be attributed to the size and structural order of the crystallites in both the chain-backbone and $\pi$-stacking directions. However, the molecular weight dependence of the mobility cannot be
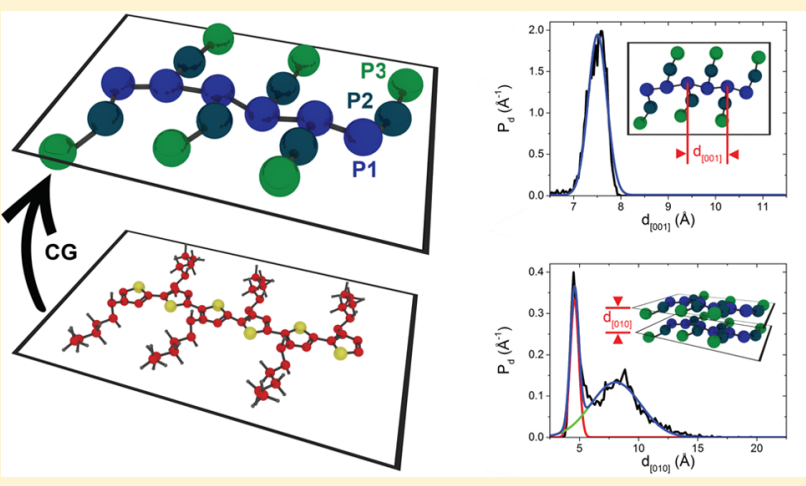
rationalized in the same way. Longer chains are shown to belong to more crystallites in the morphology, suggesting that the crystals become better connected as the molecular weight of the sample increases. We show that engineering samples to have an increased fraction of these long "tie chains" within the morphology improves mobility. As such, we propose that crystal connectivity in the noncrystalline portions of the morphology is similarly important in determining carrier mobility as crystallite size and order for semicrystalline conjugated polymers.

\section{INTRODUCTION}

Solution-processed conjugated polymers are an important class of semiconductor due to the possibility of affecting their optical and electronic properties through molecular design ${ }^{1,2}$ as well as their compatibility with scalable manufacturing processes. These versatile materials are attractive alternatives to inorganic semiconductors in applications where low cost, large area, and flexibility are needed. A fundamental property of component polymers is the charge-carrier mobility $(\mu)$, which often determines performance in electronic devices ranging from organic thin-film transistors (OTFTs) and ${ }^{5}$ light-emitting diodes (OLEDs) $)^{6,7}$ to photovoltaics (OPVs). ${ }^{8-11}$ Indeed, in some devices, low mobility currently prohibits the use of conjugated polymers in industrially important applications. ${ }^{12}$ It is therefore vital to exert control over the mobility to enable conjugated polymers to achieve their full potential. As such, the design of high mobility polymers ${ }^{13-15}$ and subsequent processing to yield high mobility morphologies ${ }^{16-18}$ is an active area of research. A significant remaining challenge is understanding the relationship between morphology on the molecular level and mobility. ${ }^{19}$ This is demonstrated by investigations of poly(3-hexylthiophene) (P3HT) - a semicrystalline polymer often used in OTFTs ${ }^{16,20}$ and photovoltaics. $^{18,21}$
As is the case for many conjugated polymers, the electronic properties of P3HT depend sensitively on the morphology. ${ }^{22}$ In the amorphous phase, P3HT exhibits a time-of-flight hole mobility of the order $\mu \sim 1 \times 10^{-5} \mathrm{~cm}^{2} \mathrm{~V}^{-1} \mathrm{~s}^{-1}$. ${ }^{23}$ However, P3HT chains can self-assemble into crystals when the film is subjected to thermal or solvent vapor annealing, or high pressure, $^{24,25}$ with the resultant semicrystalline morphologies exhibiting hole mobilities larger by at least an order of magnitude. $^{23,26,27}$ The degree to which crystals form depends also on the properties of the polymer chains such as regioregularity, ${ }^{24}$ molecular weight, ${ }^{28,29}$ and polydispersity. ${ }^{30}$ However, the collective effect of these variables on aspects of morphology, and subsequently the mobility, is complex. Many aspects of molecular morphology have been correlated with increased mobility in P3HT, such as a larger proportion of crystalline material, ${ }^{30,31}$ improved crystalline order in the $\pi$ stacking direction ${ }^{32}$ or along the backbone of the chains themselves, ${ }^{28,33,34}$ or, more recently, the presence of tie chains within the morphology linking crystals together. ${ }^{19,35,36}$ This demonstrates the challenge of determining causal relationships between mobility and morphology, since even with the benefit

Received: November 25, 2015

Revised: January 18, 2016

Published: February 22, 2016 


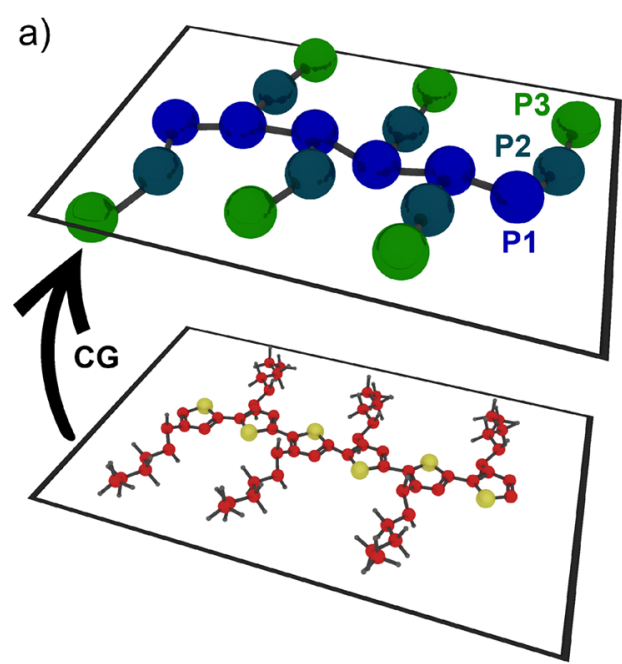

c)

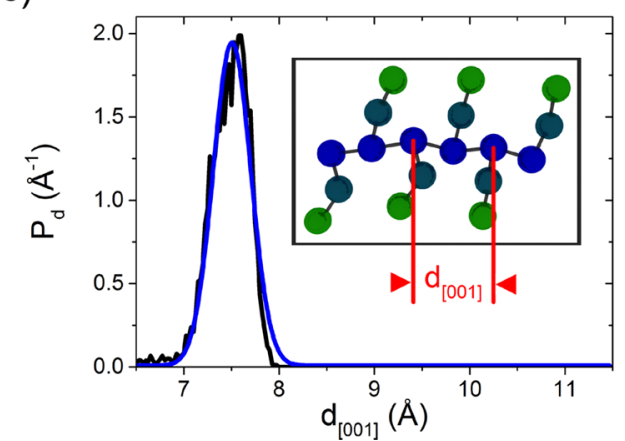

b)

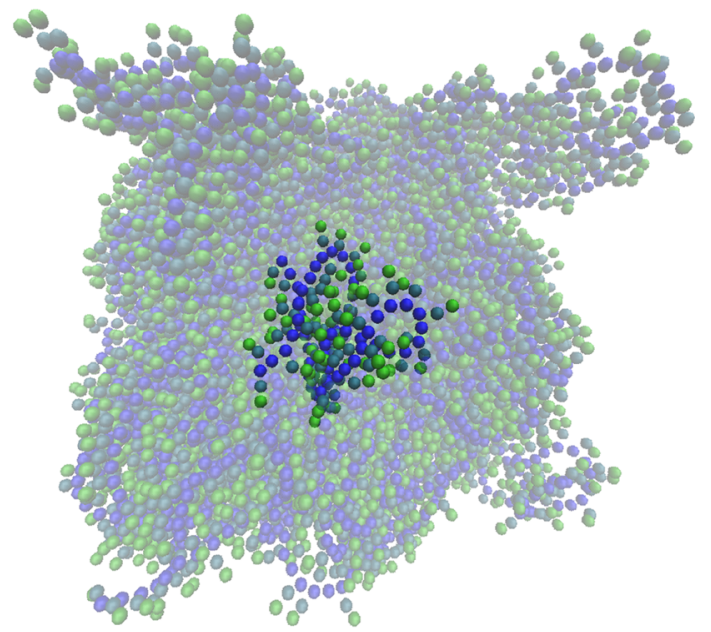

d)

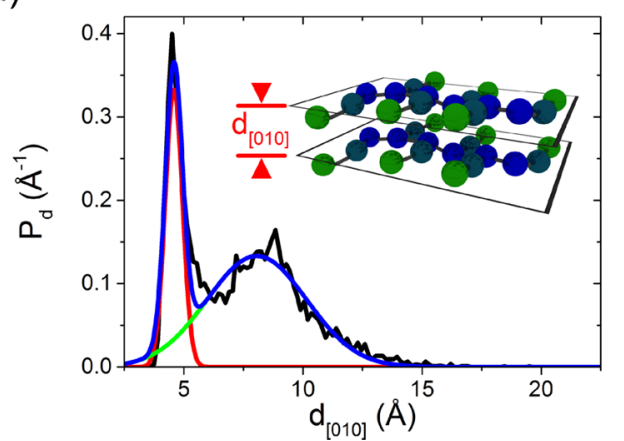

Figure 1. (a) Depiction of the coarse-graining process and naming nomenclature for the CG sites. (b-d) Results from the coarse-grained simulation of the S-51 sample, annealed at $T_{\mathrm{a}}=423 \mathrm{~K}$. (b) Sample morphology with conformation of an example chain highlighted. (c, d) $d_{[h k l]}$ histograms for the morphology, along with the corresponding Gaussian fits to the data (blue lines). (c) $d_{[001]}$ in the along-chain direction (inset: top-down schematic showing conjugation of the CG P3HT chain). (d) $d_{[010]}$ in the $\pi$-stacking direction (inset: orthographic projection showing $\pi$-stacking of CG P3HT chains).

of a battery of carefully performed experiments on a wellstudied polymer, the underlying physics is still the subject of much debate-especially in the context of crystallinity. ${ }^{37}$

Simulations offer a way to examine the relationship between molecular morphology and mobility in greater detail than is generally available by a single experiment. Of course, for such analysis to be meaningful, the descriptions of both the morphology and charge transport must be realistic. While there are a range of morphology simulation techniques, ${ }^{38,39}$ molecular dynamics (MD) methods stand out as providing morphologies with atomistic detail for experimentally relevant molecular weights and polydispersities. MD simulations use a calibrated force field to replicate the bulk behavior of chains under different processing conditions and annealing temperatures. $^{40-42}$ While some $\mathrm{MD}$ simulations model samples atomistically, an alternative method involves grouping together clusters of neighboring atoms into a single "coarse-grained" (CG) site for reduced computational cost. ${ }^{43,44}$ This is an especially important issue as computational cost limits the amount of simulated material that can be considered. CG models have been used to successfully reproduce the experimental data of chain conformation and phase behavior in conjugated polymers, ${ }^{45}$ the miscibility and interpenetration of OPV blends, ${ }^{46}$ and predicting microstructure architectures ${ }^{47}$ that can be linked to mesoscopic morphological features. ${ }^{48}$ However, to date, the detailed film morphologies generated by these techniques have not been joined with charge transport simulations. Studies have instead focused solely on either examining the film morphologies ${ }^{44}$ or charge transport in idealized morphologies. ${ }^{49,50}$

In this article, we generate realistic P3HT morphologies using CG MD simulations and use these in a charge transport model to relate structure to mobility. We simulate populations of chains that have commercially available weight-averaged molecular weights $\left(19.4 \mathrm{kDa} \leq M_{\mathrm{w}}<69.9 \mathrm{kDa}\right)$ and polydispersity indices $(1.5 \leq \mathrm{PDI}<2.4)$ for a realistic thin film density $\left(\rho=1.1 \mathrm{~g} \mathrm{~cm}^{-3}\right)$. These chains are then subjected to various annealing protocols to better understand how thin film morphology evolves. These diverse, realistic morphologies are used in kinetic Monte Carlo (KMC) charge transport simulations in which hopping rates are determined by semiempirical quantum chemical ZINDO/S calculations. Using this approach, we recreate the experimentally observed increase in P3HT hole mobility, $\mu$, when the annealing temperature, $T_{a}$, and molecular weight, $M_{\mathrm{w}}$, are increased. We show that the observed annealing temperature dependence of $\mu$ is correlated with increasing volume of crystals, and better intrachain crystal order, although not crystal order in the $\pi$ stacking direction. Conversely, we find that the observed $M_{\mathrm{w}}$ dependence of $\mu$ cannot be explained by these aspects of the morphology. Instead, we show the improvement in $\mu$ as a function of $M_{\mathrm{w}}$ is largely due to the presence of tie chains 
Table 1. P3HT Samples Considered in This Investigation with Number- and Weight-Averaged Molecular Weights $\left(M_{n}, M_{w}\right)$ and Polydispersity Indices (PDI), Zero-Field Hole Mobilities $\left(\mu_{0}\right), \pi$-Stacking Paracrystallinities $\left(g_{[010]}\right)$, Intrachain Paracrystallinities $\left(g_{[001]}\right)$, and Crystal Proportions $(\gamma)$ for Samples Annealed at the Maximum Considered Temperature, $623 \mathrm{~K}^{a}$

\begin{tabular}{|c|c|c|c|c|c|c|c|c|c|c|}
\hline name & S-19 & S-37 & S-46 & S-51 & S-57 & S-70 & M-5 & M-10 & M-20 & M-50 \\
\hline$M_{\mathrm{w}}(\mathrm{kDa})$ & 19.4 & 37.0 & 45.7 & 51.1 & 56.8 & 69.9 & 37.3 & 45.7 & 51.2 & 57.0 \\
\hline$M_{\mathrm{n}}(\mathrm{kDa})$ & 12.6 & 20.0 & 27.8 & 29.5 & 30.1 & 45.0 & 15.9 & 18.8 & 21.8 & 26.4 \\
\hline PDI & 1.5 & 1.9 & 1.6 & 1.7 & 1.9 & 1.6 & 2.3 & 2.4 & 2.3 & 2.2 \\
\hline$\mu_{0}\left(1000 \mathrm{~cm}^{2} \mathrm{~V}^{-1} \mathrm{~s}^{-1}\right)$ & 2.40 & 2.99 & 3.80 & 3.97 & 3.38 & 4.67 & 3.23 & 3.26 & 4.38 & 4.21 \\
\hline$g_{[010]}(\%)$ & 7.51 & 7.76 & 8.76 & 8.36 & 8.72 & 8.73 & 7.85 & 8.55 & 9.80 & 8.19 \\
\hline$g_{[001]}(\%)$ & 1.93 & 2.06 & 2.17 & 2.26 & 2.08 & 2.14 & 2.02 & 2.14 & 2.48 & 2.29 \\
\hline$\gamma(\%)$ & 44.15 & 45.43 & 43.06 & 44.17 & 45.55 & 43.51 & 43.26 & 42.5 & 45.58 & 43.19 \\
\hline
\end{tabular}

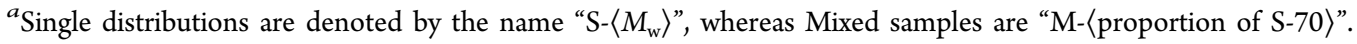

linking together crystallites within the morphology, which provide improved charge transport through the amorphous regions. This suggests a model of mobility in semicrystalline conjugated polymers that is jointly determined by transport in the crystal (dependent on crystal size and order) and the availability of connecting tie chains, which are a subset of the otherwise noncrystalline regions of the film. Although P3HT is used as a test case in this investigation, the conclusions are expected to be generally relevant for other semicrystalline polymers such as poly(2,5-bis(3-tetradecylthiophen-2-yl)thieno[3,2-b]thiophene) (PBTTT) and poly(5,5'-bis(3-alkyl2-thienyl)-2,2'-bithiophene) (PQT), which have been shown to exhibit similar transport activation energies. ${ }^{19}$

\section{SIMULATIONS}

The coarse-grained (CG) simulation model of regioregular P3HT represents each monomer by three spherical sites that correspond to the thiophene ring (P1), first three hexyl sidechain methyl groups (P2), and last three side-chain methyl groups (P3) (Figure 1a) and was parametrized to reproduce the local structure of an accurate atomistic P3HT model. ${ }^{45,51}$ We note that as three coarse-grained sites are used, the monomers are anisotropic, and so chains are still permitted to self-assemble despite each site being spherical. A closely related CG model of P3HT with the same bonded interactions (which most strongly determine the polymer melt structure), but with nonbonded interactions that describe an implicit anisole solvent, has previously been shown to capture thermodynamic and nanoscale structural properties of solution-phase P3HT well. $^{45}$ The CG model of pure regioregular P3HT derived here captures the structural properties of $\mathrm{P} 3 \mathrm{HT}$ oligomers in the atomistic model over a wide range of thermodynamic conditions, as shown in Supporting Information section S1.

A database of P3HT chains with polymerization lengths ranging from 2 to 1000 monomers (330 Da-164 kDa) was generated. These chains were permitted to relax within the MD simulations for $1 \mathrm{~ns}$ in isolation at $290 \mathrm{~K}$, according to the intramolecular components of the force field, thus mimicking their arrangement within solution. A total of 40 relaxed chains were then selected at random from a custom chain distribution (Supporting Information section S2) to yield weight-averaged molecular weight $\left(M_{\mathrm{w}}\right)$ and polydispersity similar to those available commercially (e.g., Sigma-Aldrich, Reike Metals). It was found that the commonly used Schulz-Flory distribution ${ }^{52}$ did not adequately describe the combination of large molecular weights and high polydispersities expected in P3HT samples.

This process was repeated to give a range of samples with $19 \leq M_{\mathrm{w}}<70 \mathrm{kDa}$, which are named S-19 to S-70, respectively, as shown in Table 1 . The selected chains, representing a particular P3HT sample, were then placed in a large, periodically bounded simulation box at random positions and orientations, with sufficient empty space between chains to avoid interchain interactions. This large simulation volume was then compressed over a period of $40 \mathrm{ps}$ at $290 \mathrm{~K}$, until the density $(\rho)$ reached the average P3HT film density of $1.1 \mathrm{~g}$ $\mathrm{cm}^{-3}$. ${ }^{3}$ This mimicked the effect of solvent evaporation, producing a CG morphology containing $\mathrm{P} 3 \mathrm{HT}$ chains with realistic $M_{\mathrm{w}}$, PDI, and $\rho$, occupying a cube with sides of the order $10 \mathrm{~nm}$. The exact simulation volumes varied with $M_{\mathrm{w}}$ but were all of similar order to thin film thickness in real devices. $^{18,44}$ An example morphology is depicted in Figure $1 \mathrm{~b}$, with a single chain highlighted to show expected conformation within the force field.

The CG morphologies then underwent a series of annealing and equilibration MD simulations utilizing both the intra- and intermolecular components of the force field. All simulations were performed at constant volume and temperature, maintained using a Nosé-Hoover thermostat and barostat ${ }^{54}$ and timesteps of $4 \mathrm{fs}$, using the LAMMPS suite. ${ }^{55}$ The morphologies were first simulated at a temperature $T_{a}$ varying from $T_{\mathrm{a}}=290 \mathrm{~K}$ (no annealing) to $T_{\mathrm{a}}=623 \mathrm{~K}$ for $4 \mathrm{~ns}$. Of course, real devices are annealed for much longer; however, we observed that the total potential energy and structural distribution functions reached constant values within this time scale (Supporting Information section S3), suggesting that some level of thermally activated chain reorganization had taken place. The 4 ns annealing time was imposed due to the computational cost of the MD simulation. To mitigate the effect of the reduced annealing time, $T_{\mathrm{a}}$ values exceeding those used in experiment were also used to increase the energy transferred to the system during this time, ${ }^{44,56}$ although it was found that $T_{\mathrm{a}}>623 \mathrm{~K}$ resulted in numerical instabilities in the $\mathrm{MD}$ simulations for the chosen time step. Annealed films were allowed to cool down to room temperature over a further $4 \mathrm{~ns}$ period, before equilibrating at $T_{\mathrm{a}}=290 \mathrm{~K}$ for a final $4 \mathrm{~ns}$.

The physical conformation of the chains in the equilibrated system was then analyzed to determine the crystal structure of the samples. Crystals in the morphology were identified by determining the proximity of conjugated subunits (i.e., CG site $\mathrm{P} 1$ - the thiophene ring in each monomer) to others in the morphology, given an initial crystal direction described by the vector $[h k l]$. For each subunit, $d_{[h k l]}$ was defined as the separation to the closest thiophene ring lying within a cone of apex angle $30^{\circ}$ protruding both above and below the CG site in the $[h k l]$ direction. This was calculated along both the $\pi$ stacking axis $\left(d_{[010]}\right)$ and the chain backbone axis $\left(d_{[001]}\right)$, based on the positions of the bonded alkyl side chain and nearestneighbor thiophene rings. 
Figures $1 \mathrm{c}, \mathrm{d}$ show the $d_{[h k l]}$ histograms for the S-51 sample annealed at $423 \mathrm{~K}$. The $d_{[001]}$ data, which quantify along-chain order, are unimodal and can be fit by a Gaussian with mean, $\bar{d}_{[001]}=7.5 \AA$, and variance, $\sigma_{[001]}=0.2 \AA$. However, the $d_{[010]}$ data are better described by a bimodal distribution. We ascribe one peak to the crystalline portion of the morphology (fitted by a Gaussian with $\bar{d}_{[010]}=4.6 \AA$, $\sigma_{[010]}=0.4 \AA$ ) and the other to the less ordered regions of the morphology (fitted by a Gaussian with $\bar{d}_{\mathrm{a}}=8.1 \AA$, $\sigma_{\mathrm{a}}=2.1 \AA$ ). These data and our interpretation agree with the literature since both $\bar{d}_{[001]}$ and crystalline $\bar{d}_{[010]}$ fit well the grazing incidence wide-angle X-ray scattering (GIWAXS) data which report $\bar{d}_{[001]}=7.7 \AA$ and $\bar{d}_{[010]}$ $=3.8 \AA^{57}$ as well as atomistic MD simulation data which report $\bar{d}_{[001]}=7.9 \AA$ and $\bar{d}_{[010]}=4.0 \AA \AA^{50}$ Hence, the generated morphologies show crystal packing in agreement with experiment.

From the $d_{[010]}$ distributions, the chain backbone and $\pi$ stacking paracrystallinities ${ }^{58}$ were calculated as $g_{[001]}=\sigma_{[001]} /$ $\bar{d}_{[001]}$ and $g_{[010]}=\sigma_{[010]} / \bar{d}_{[010]}$, respectively, where only the narrow, crystalline distribution is considered for the $\pi$-stacking direction, as this is the region probed by XRD methods. The crystal proportion $(\gamma)$ within the morphology was approximated by determining the integral underneath the crystalline Gaussian curve as a proportion of the integral under the whole distribution. Later, we will show that $\gamma$ can be affected by both $M_{\mathrm{w}}$ and $T_{\mathrm{a}}$. However, while the current morphologies have realistic dimensions, it is important to note that the short annealing time will have reduced the opportunity for crystals to form and hence limit $\gamma$. The crystals formed here were necessarily smaller than $10 \mathrm{~nm}$ in extent and so were smaller than some reports on P3HT experimental films.

Having related the supramolecular structure of the CG morphologies to variations in $M_{\mathrm{w}}$ and $T_{\mathfrak{a}}$ we now move on to identifying links between these properties and the simulated hole mobility of the morphology. As such, we implemented a geometrical "fine-graining" procedure to approximate the atomic positions based on the CG morphologies (the full details of which are given in Supporting Information section S4). This atomistic representation is required in order to calculate electronic couplings that were ultimately used for the kinetic Monte Carlo model. Briefly, the fine-graining procedure was implemented by manipulating an energetically minimized atomistic template of a thiophene ring to produce a $100 \%$ regioregular chain backbone, with intermonomer torsion determined using the positions of the bonded neighboring CG sites. The manipulation was repeated for every monomer in the chain, resulting in an atomistic polythiophene chain with thiophene ring positions and orientations corresponding to the CG MD outputs, an example of which is shown in Supporting Information section S4. Given that the solubilizing alkyl side chains only affect the charge mobility characteristics by constraining the self-organization properties of the backbone itself, $^{59-61}$ we omitted the consideration of the side chains in the transfer integral calculations for simplicity.

Calculations of the density of states (DoS) for P3HT have shown that the orbital density localization is around seven monomers. ${ }^{56,62}$ In our semiclassical charge transport model, we assumed that holes hop between these segments of increased orbital overlap. As such, the polythiophene chains were split into segments by considering the "chain backbone" vector between centers-of-mass of adjacent thiophene rings, starting at one end of the chain. If the angle between the chain backbone vector and the vector to the next thiophene along in the chain was within a tolerance angle $\theta_{\mathcal{c}}$, the thiophene units were assumed to be part of the same delocalized segment; otherwise, the thiophene unit was assumed to be part of a new segment. $\theta_{\mathrm{c}}$ was selected such that the hole was, on average, delocalized over seven monomers for the S-57 sample and then kept constant for all morphologies. This segmentation of the chains is an approximation since the HOMO wave functions are not calculated directly. However, the mean delocalization fits with more rigorous calculations via $\theta_{c^{c}}{ }^{56,63}$ Segments were then sorted into pairs of hopping partners, i.e., two segments that were within $r_{\max }=20 \AA$ of each other including the periodic boundary conditions, which is much larger than the $\bar{d}_{[010]}$ and $\bar{d}_{\mathrm{a}}$ spacings. Quantum chemical ZINDO/S calculations were then performed on each segment individually, as well as all the hopping partner pairs, in order to calculate the molecular orbitals $^{64}$ using the ORCA program suite. ${ }^{65}$ These allowed the electronic coupling transfer integral $\left|J_{i j}\right|$ to be calculated:

$$
\left|J_{i j}\right|=\frac{1}{2} \sqrt{\left(E_{\text {HOMO }}-E_{\text {HOMO-1 }}\right)^{2}-\left(\Delta E_{i j}\right)^{2}}
$$

where $\left(E_{\text {HOMO }}-E_{\text {HOMO-1 }}\right)$ denotes the HOMO splitting energy for the dimer containing the two hopping partners and $\Delta E_{i j}$ is the difference in energy between the initial and final sites. Like some other quantum chemical calculations, ${ }^{63}$ we found the DoS to be approximately Gaussian, but significantly broader than those expected in real devices. ${ }^{27,33,66}$ Using these values to calculate $\Delta E_{i j}$ led to imaginary transfer integrals which made the charge transport simulations unrealistic. Some studies utilize Koopmans' approximation, ${ }^{67}$ in order to set $\Delta E_{i j}=0$ by assuming that isolated segments have the same energy. ${ }^{68,69}$ While Koopmans' approximation provides good agreement with density functional theory results for a variety of systems, ${ }^{70,71}$ it nonetheless discards relevant information about the energy levels of the segments, which in turn are dependent on the morphologies of interest and argued to be very important in determining mobility. ${ }^{19}$ To resolve this issue, we used an approximate method where the ZINDO/Scalculated HOMO levels were mapped onto the experimentally determined DoS (Supporting Information section S5), such that the sigma within the distribution (e.g., \pm 1 standard deviation from the mean) was retained. Note that this mapping was only used to determine $\Delta E_{i j}$ for the transfer integral and the subsequent Marcus hopping rate in eqs 1 and 2; the HOMO splitting calculation was left unmapped from the simulated molecular orbitals.

The transfer integral was then used to determine the rate at which hops could take place, given by the semiclassical Marcus expression: ${ }^{72}$

$$
k_{\text {hop }}=\frac{\left|J_{i j}\right|^{2}}{\hbar} \sqrt{\frac{\pi}{\lambda_{i j} k_{\mathrm{B}} T}} \exp \left[-\frac{\left(\Delta E_{i j}-\lambda_{i j}\right)^{2}}{4 \lambda_{i j} k_{\mathrm{B}} T}\right]
$$

where $k_{\mathrm{B}}$ is the Boltzmann constant, $T$ is the absolute temperature, and the reorganization energies, $\lambda_{i j}$, were estimated using a model predicted from DFT calculations based on the length of the host segment (Supporting Information section S6). ${ }^{73}$ Section S6 also includes a comparison of the transfer integral calculations from other studies, which are shown to match well the values used here. Note that the transfer integrals between all segment pairs with separation $r<r_{\max }$ in the morphology were considered, thereby implicitly allowing variable range hopping. ${ }^{74}$ 
The charge transport simulations themselves consisted of a KMC algorithm that calculated the wait time until the next hopping event using the equation

$$
\tau=-\frac{\ln x}{k_{\text {hop }}}
$$

where $x$ is a uniformly distributed random number between 0 and 1 and $k_{\text {hop }}$ is the Marcus hopping rate calculated from eq 2. In each simulation, a single hole was injected onto a random segment within the morphology and permitted to hop through the system for a time $t_{\max }$. The mean-squared displacement $\left(\left\langle x^{2}\right.\right.$ \rangle$)$ was calculated and the process repeated $10^{4}$ times. $\left\langle x^{2}\right\rangle$ was shown to be directly proportional to $t_{\max }$, with proportionality corresponding to the $3 \mathrm{D}$ diffusion coefficient $D$. The related zero-field hole mobility, $\mu_{0}$, for the morphology was calculated using

$$
\mu_{0}=\frac{q D}{k_{\mathrm{B}} T}
$$

where $q$ is the elementary charge.

\section{RESULTS AND DISCUSSION}

Figure 2 shows the simulated $\mu_{0}$ for various P3HT samples used in this investigation (Table 1) as functions of annealing temperature, $T_{a}$ and weight-averaged molecular weight, $M_{\mathrm{w}}$. First, it is important to note that the absolute values of the mobilities recorded here are several orders of magnitude greater

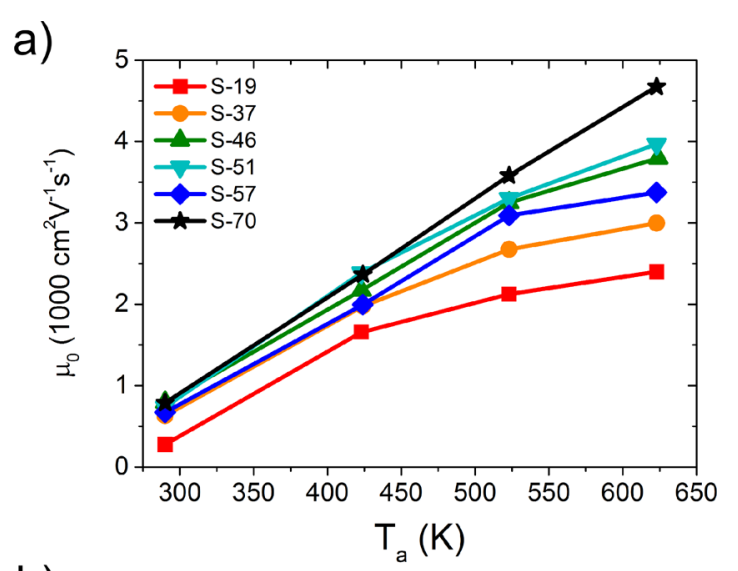

b)

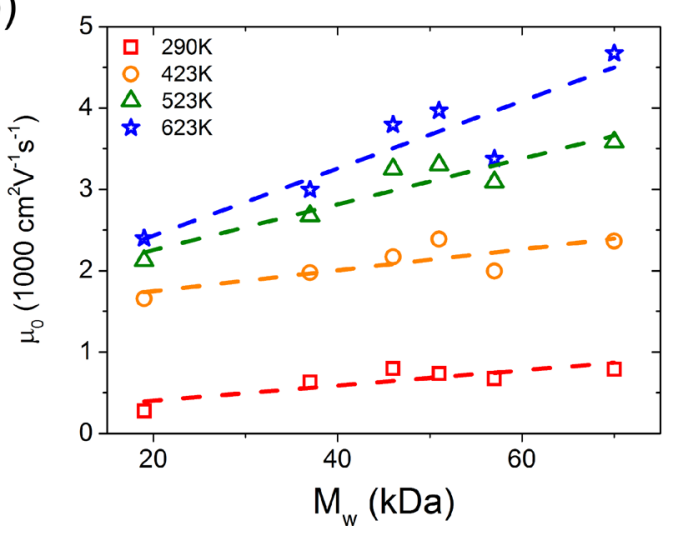

Figure 2. (a, b) The zero-field hole mobility for single distribution samples with different molecular weights (as given in Table 1) as functions of (a) annealing temperature $\left(T_{\mathrm{a}}\right)$ and (b) molecular weight $\left(M_{\mathrm{w}}\right)$. than other time-of-flight measurements obtained from real devices. These tend to report mobilities within the range $2 \times$ $10^{-4}-2 \times 10^{-3} \mathrm{~cm}^{2} \mathrm{~V}^{-1} \mathrm{~s}^{-1}$ for highly regioregular pristine P3HT films at zero to low fields $\left(F \simeq 4 \times 10^{6} \mathrm{~V} \mathrm{~m}^{-1}\right)$, depending on the processing regime. ${ }^{23,26,27}$ However, it is reasonably common for $a b$ initio calculations of mobility to differ from experiment by some orders of magnitude due to the significant challenge of modeling a complex, disordered system. $^{75,76}$ Our focus here is how molecular morphology influences mobility through $M_{w}, T_{a}$, and the PDI. Hence, we now move on to consider relative changes in mobility and how this compares with experiment.

While the data show some scatter, there is a clear monotonic trend of increasing $\mu_{0}$ with both $M_{\mathrm{w}}$ and $T_{\mathrm{a}}$. The improvement in $\mu_{0}$ is shown to saturate beyond $\sim 450 \mathrm{~K}$ to an extent that depends on $M_{\mathrm{w}}$, with smaller $M_{\mathrm{w}}$ showing more pronounced saturation. $T_{\mathrm{a}}=423 \mathrm{~K}$ is a common annealing temperature, for which it has been shown that $\mu_{0}$ is larger by a factor of $2-3$ when compared to as-cast films. ${ }^{77,78}$ These data agree reasonably well with the predicted improvement in $\mu_{0}$ by a factor of 3.5 shown here. The mobility is also sensitive to $M_{w}$, as increasing $M_{\mathrm{w}}$ from 19 to $70 \mathrm{kDa}$ increases $\mu_{0}$ by a factor of 3.2 for unannealed samples and a factor of 2.1 for morphologies annealed at $623 \mathrm{~K}$. Some field-effect transistor measurements on samples of unannealed P3HT have reported that an increase in $M_{\mathrm{w}}$ from 11 to $51 \mathrm{kDa}$ results in an increase in saturation mobility of around 1 order of magnitude ${ }^{79}$ or a factor of 5 over the range $21 \leq M_{\mathrm{w}}<61 \mathrm{kDa}{ }^{80}$ For transistors annealed at $T_{\mathrm{a}}=$ $370 \mathrm{~K}$, mobilities have been reported to increase by a factor of $\sim 3$ for the range $20 \leq M_{\mathrm{w}}<76 \mathrm{kDa}{ }^{81}$ However, time-of-flight mobility investigations for unannealed films show that the mobility actually decreases by a factor of 5 as $M_{\mathrm{w}}$ is increased from 26 to $72 \mathrm{kDa} .{ }^{33}$ It is difficult to be exact in comparing the current data to experiment due to the variety of protocols used; however, it is clear that the general trend of increasing $\mu$ with $M_{\mathrm{w}}$ is reproduced. The change in $\mu_{0}$ with $M_{\mathrm{w}}$ is smaller than most reports; however, this might be expected due to shorter annealing times. We note again that in our model we have made simplifying assumptions to allow charge transport simulations on realistic thin films. Despite this, we note that the model has recreated the relative changes in $\mu_{0}$ with temperature and molecular weight, as seen in experiment. In order to determine the reason for the observed mobility trends in Figure 2 and that of previous studies, we now consider the morphological structure of the P3HT film.

The results of the paracrystallinity measurements for the single distributions are shown in Figure 3. Along the polymer backbones, the disorder is shown to decrease as the annealing temperature increases, characterized by a narrowing $d_{[001]}$ distribution. Regular lattice spacings in this direction result in strong coherence between adjoining hole delocalization segments, manifesting as an increase in the average segment length, $L$ (Figure 3c). A combination of these factors could explain the observed increasing mobility with increasing annealing temperature (Figure 2). However, we note that Figure 3a does not show a monotonically decreasing $g_{[001]}$ as a function of increasing molecular weight. The $g_{[010]}$ data shown in Figure $3 \mathrm{~b}$ lie within $7 \% \leq g_{[010]}<10 \%$ and show a slight reduction with increasing $T_{\mathrm{a}}$ and no clear trend with $M_{\mathrm{w}}$. This is in agreement with sources in the literature that suggest that P3HT $\pi$-stacking disorder is high and mostly independent of degree of polymerization beyond 100 monomer units $\left(M_{\mathrm{w}}=16\right.$ $\mathrm{kDa})^{19}$ as well as XRD data for semicrystalline polymer 


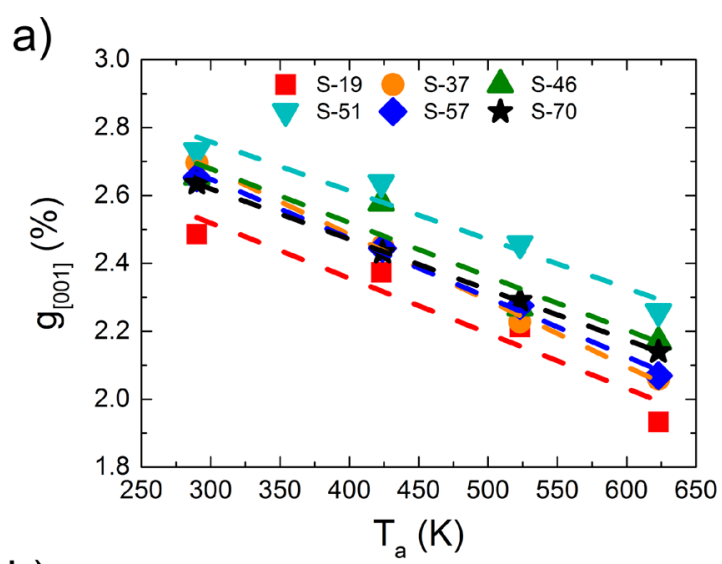

b)

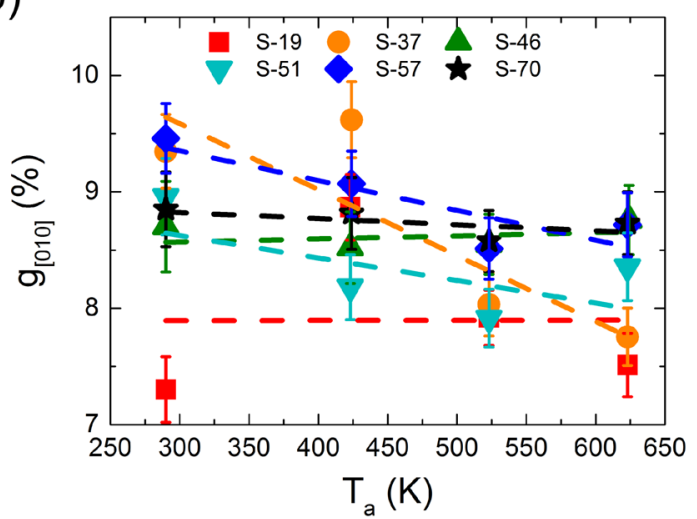

c)

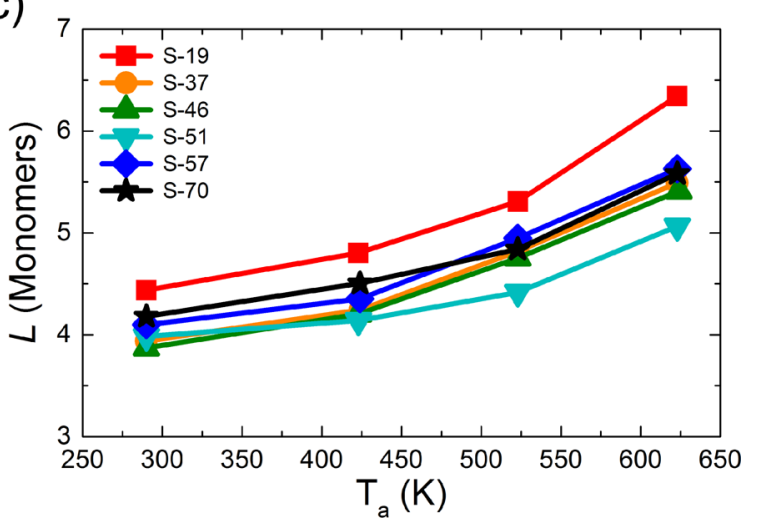

Figure 3. $(a, b)$ Paracrystallinity $(g)$ for the investigated samples as a function of annealing temperature, $T_{a}$, for the (a) [001] and (b) [010] directions. Linear fits to the data are also shown. Note that the highly uniform Gaussian distributions for the along-chain data result in very small error bars that are barely visible on these axes. (c) The variation in average segment length, $L$, as a function of annealing temperature, $T_{a}$ for each morphology.

films ${ }^{50,82}$ such as poly(bithiophene-alt-thienothiophene) (PBTTT). ${ }^{83,84}$ GIWAXS measurements on thick $(\sim 100 \mathrm{~nm})$ films annealed at $413 \mathrm{~K}$ have shown that $\mathrm{P} 3 \mathrm{HT}$ generally exhibits a slightly lower paracrystallinity $g \sim 5 \%,{ }^{85}$ suggesting that our morphologies are more disordered than equivalent experiments but still lie within the semicrystalline regime. ${ }^{82}$

Although we find correlations between $g_{[001]}$ and $T_{a}$, and hence $\mu_{0}$, there is no clear dependence of $g_{[001]}$ or $g_{[010]}$ on $M_{\mathrm{w}}$, even though $\mu_{0}$ does vary with $M_{\mathrm{w}}$. This may be exacerbated by the short annealing times that are used in the current investigation, but it does seem to indicate that not all of the mobility trends observed in Figure 2 can be solely explained by the paracrystallinity along either axis. This again is in agreement with morphological studies that have suggested that the $\pi$ stacking paracrystallinity does not affect the mobility. ${ }^{19,49}$

The $d_{[010]}$ distributions shown in Figure $1 \mathrm{~b}$ also allow an estimation of the volume occupied by the crystal regions. To do this, we measure the "crystal cutoff" $\left(d_{\text {cut }}\right)$ for the morphology as the value of $d_{[010]}$ corresponding to the minimum value for the combined bimodal distribution (around $6 \AA$ for all morphologies). Thiophene spacings $d_{[010]}<d_{\text {cut }}$ are considered as belonging to a crystal, whereas thiophene with $d_{[010]}>d_{\text {cut }}$ belong to the amorphous region of the morphology. We then define the crystal proportion, $\gamma$, as the integral of the $d_{[010]}$ distribution up to $d_{\text {cut }}$ as a fraction of the integral of the whole distribution.

Figure 4 shows $\gamma$ as functions of both $T_{\mathrm{a}}$ and $M_{\mathrm{w}}$. The absolute values of $\gamma$ are around 0.2 lower than those reported from melting enthalpy calculations, ${ }^{30}$ again likely because those devices were annealed for a much longer period than the current simulations. In general, Figure 4 shows that $\gamma$ increases linearly with annealing temperature as expected. By contrast, $\gamma$ shows no clear dependence on $M_{\text {w }}$.

Differential scanning calorimetry (DSC) measurements of the enthalpy of fusion have shown that the expected degree of crystallinity remains approximately constant for $17 \leq M_{\mathrm{w}}<93$ $\mathrm{kDa}$ at room temperature. ${ }^{86} \mathrm{~A}$ different study of smaller molecular weights showed that the volume occupied by crystals increased from $4.5 \%$ at $M_{\mathrm{w}}=2.6 \mathrm{kDa}$ to $18 \%$ at $M_{\mathrm{w}}=27 \mathrm{kDa}{ }^{31}$ Perhaps then it is unsurprising that for the current data in the range $19 \leq M_{\mathrm{w}}<70 \mathrm{kDa}$ and considering the short annealing times, $\gamma$ varies by a maximum of $5 \%$ for unannealed devices and even less for films annealed at increased $T_{\mathrm{a}}$. Again, as with the paracrystallinity measurements, we find that increasing $T_{\mathrm{a}}$ is correlated to an increased crystal proportion in the film, which may partly explain the observed increase in $\mu_{0}$ with respect to $T_{\mathrm{a}}$. However, we also find no clear trend relating $\gamma$ to $M_{\mathrm{w}}$ for the examined conditions even though $\mu_{0}$ is shown to clearly increase with $M_{\mathrm{w}}$.

It has been argued that high mobility is caused not only by the size of well-ordered crystals but also by the presence of "tie chains" that form efficient connections between them. ${ }^{19}$ To show the impact of tie chains in the current data, Figure 5 shows the number of crystals each chain participates in $(\zeta)$ as a function of polymerization, $D_{\mathrm{p}}$. We observe that increasing $M_{\mathrm{w}}$ increases the likelihood that individual chains will participate in more crystals. Furthermore, it can also be seen that this trend is largely unaffected by the annealing temperature. We therefore propose that the observed $M_{\mathrm{w}}$ dependence of $\mu_{0}$, which is not explained by the crystalline order or crystallite size, is instead due to the population of long polymer chains which link together many crystallites, in agreement with Noriega et al. ${ }^{19}$ Implicit in this argument is that the non-crystalline regions of the film are divided into tie chains, which are members of many crystals and benefit mobility, and shorter chains, which are members of fewer crystals and therefore do not benefit mobility. This suggests semicrystalline conjugated polymer mobility can be optimized by increasing the number of tie chains in the noncrystalline phase.

To test this hypothesis, films were generated in which there existed an increased population of tie chains in an otherwise small molecular weight sample. Proportions of the S-19 and S-70 samples were mixed together to produce systems of similar $M_{\mathrm{w}}$ to the single distributions, but with polydispersities ranging between $2.2 \leq \mathrm{PDI}<2.4$. These samples are denoted 
a)

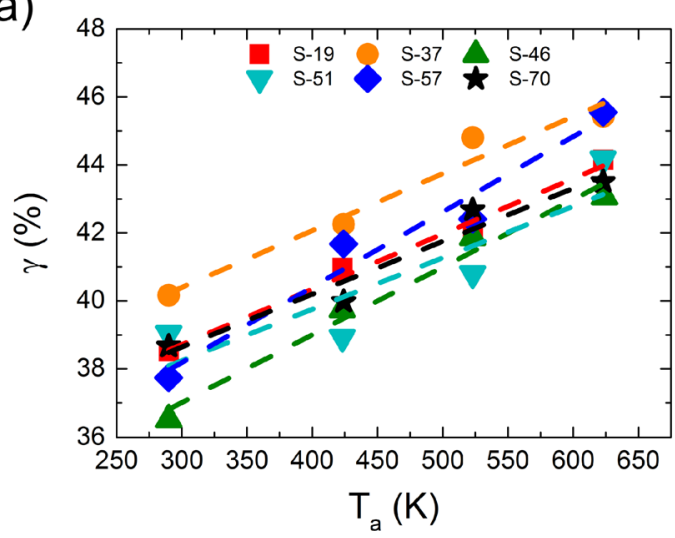

b)

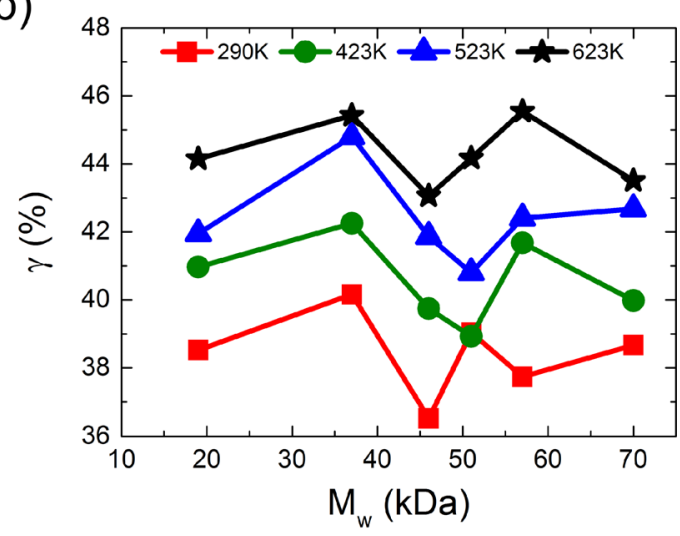

Figure 4. (a, b) The $\pi$-stacking crystal proportion $(\gamma)$ for the investigated samples as a function of (a) annealing temperature $\left(T_{\mathrm{a}}\right)$ and $(\mathrm{b})$ molecular weight $\left(M_{\mathrm{w}}\right)$. Linear fits to the data are shown for the temperature response.

a)

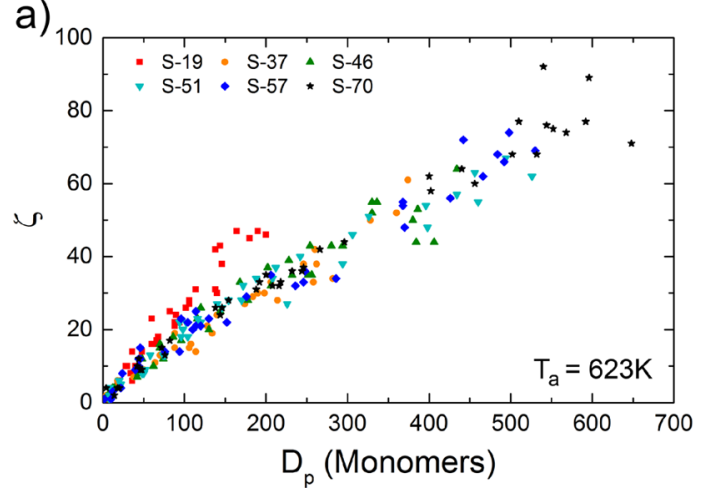

b)

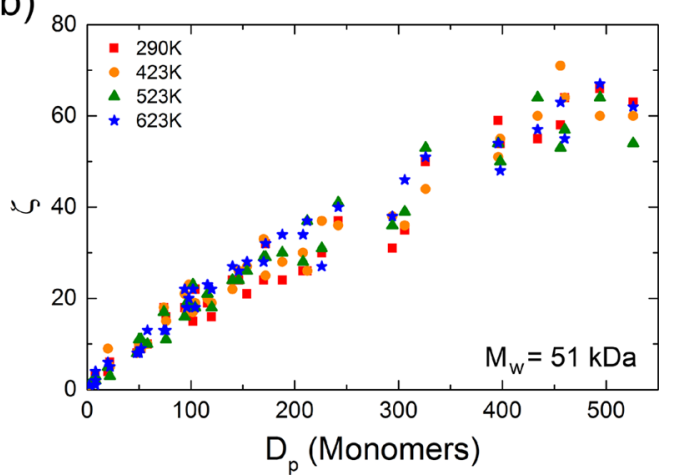

Figure 5. (a, b) The functional relationship between the number of participant crystals of each chain, $\zeta$, and its degree of polymerization, $D_{\mathrm{p}}$. Data are shown for single-distribution morphologies with (a) varying $M_{\mathrm{w}}$ annealed at $T_{\mathrm{a}}=623 \mathrm{~K}$ and (b) varying $T_{\mathrm{a}}$ for samples with $M_{\mathrm{w}}=51 \mathrm{kDa}$.

in Table 1 by $M-X$, where $X$ is the wt \% of $S-70$ incorporated into the S-19 morphology. Figures $6 a, b$ show that the population of high- $\zeta$ tie chains has been successfully increased by adding a small number of chains from the S-70 morphology to the S-19 sample, as predicted by experiment. ${ }^{19,35,36}$ The tie chains in the mixed morphologies generally belong to more crystals than those within single-distribution morphologies of the same $M_{\mathrm{w}}$. As with the single-distribution samples, there is no $T_{\mathrm{a}}$ dependence of $\zeta$, suggesting that the effect of added chains is largely to join crystals together rather than change crystal properties.

Figures $6 c$,d show the mobilities for the resultant mixed morphologies, along with corresponding single distributions of equivalent $M_{\mathrm{w}}$. Increasing the proportion of long chains within the morphology by mixing is shown to increase the mobility, and indeed, mixed morphologies are shown to have a comparable mobility to single-distribution samples of the same $M_{\mathrm{w}}$. This suggests that it is possible to make a low $M_{\mathrm{w}}$ sample behave like a high $M_{\mathrm{w}}$ sample through the addition of longer chains, which "tie" the crystallites together. In turn, the data indicate that increasing the polydispersity of semicrystalline polymers can have beneficial effects on the electrical performance. While tie chains have been introduced here by engineering the distribution of $M_{w}$, we note that similar effects could be achieved in conjugated polymers with increased persistence length and rigidity. ${ }^{87}$

\section{CONCLUSIONS}

To conclude, we have used coarse-grained molecular dynamics simulations of realistic samples of P3HT chains to obtain thin film morphologies for a variety of annealing temperatures. The morphologies then underwent a fine-graining procedure, returning them to the atomistic representation so that the semiempirical ZINDO/S method could be used to determine the charge transport characteristics of the thin films. Hole mobilities at zero field were calculated and showed that the mobility increases both when the annealing temperature and weight-averaged molecular weight of the sample were increased, in accordance with experimental results. The crystal structure of the morphologies was then analyzed to help explain these dependencies.

Both the crystalline order along the chain and the volume proportion of crystals within the morphology, $\gamma$, were shown to increase with increasing annealing temperature, suggesting that as devices are annealed at higher temperatures, more and better ordered crystals are produced, increasing the hole mobility. The $\pi$-stacking crystalline order was shown to increase slightly with increasing temperature, indicating that although well-ordered $\pi$ stacking crystals can contribute slightly to the observed mobility dependence on temperature, it is less important than the other crystal properties, as determined by some experimental investigations.

Conversely, the molecular weight dependence of the mobility could not be explained by along-chain or $\pi$-stacking disorder, or $\gamma$. It was found that as the molecular weight increases, the 
a)

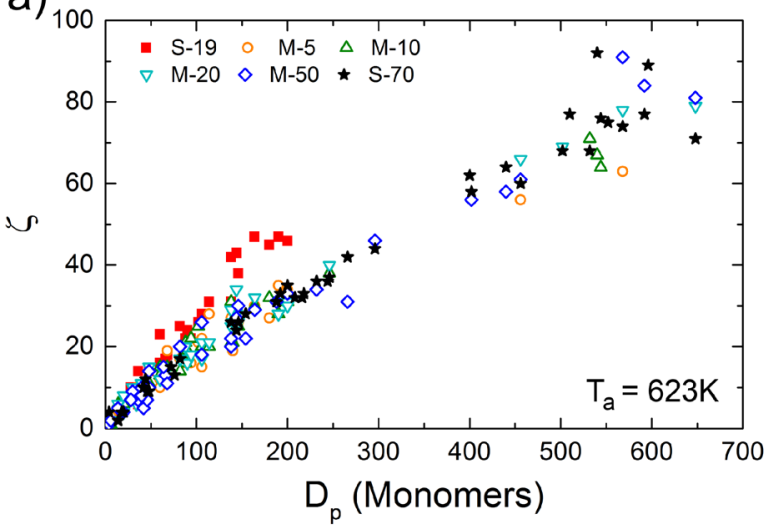

c)

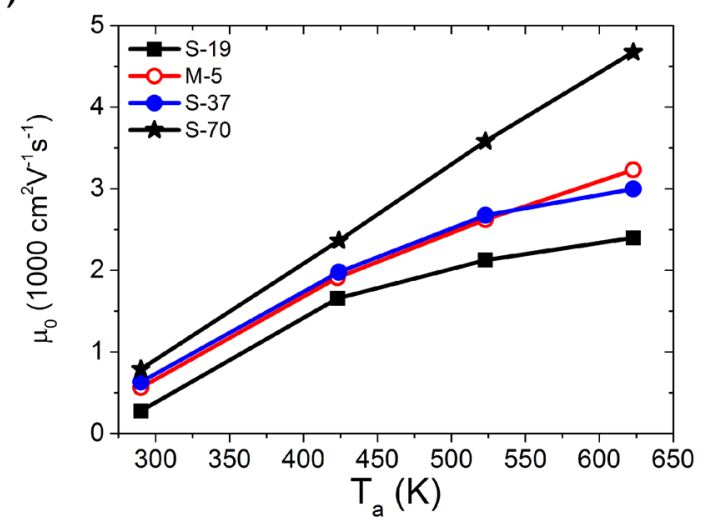

b)

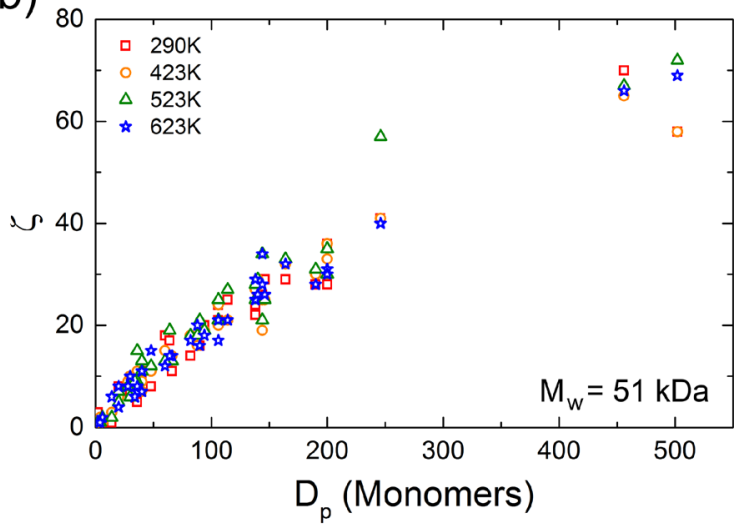

d)

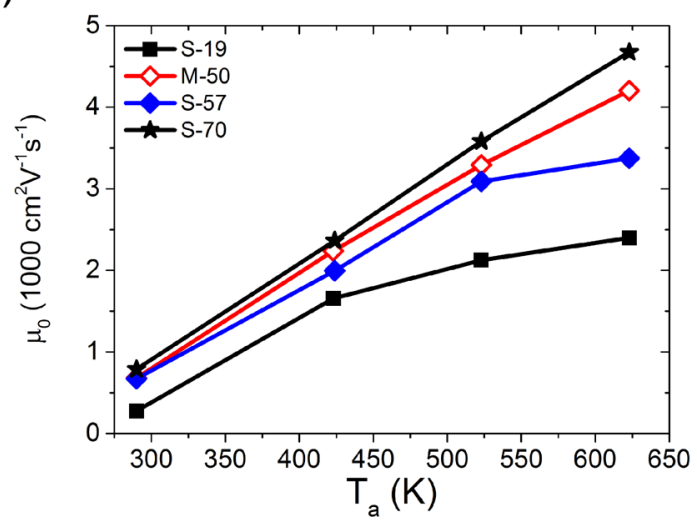

Figure 6. (a, b) The functional relationship between the number of participant crystals of each chain, $\zeta$, and its degree of polymerization, $D_{\mathrm{p}}$. Data are shown for mixed morphologies with (a) varying $M_{\mathrm{w}}$ annealed at $T_{\mathrm{a}}=623 \mathrm{~K}$ and (b) varying $T_{\mathrm{a}}$ for samples with $M_{\mathrm{w}}=51 \mathrm{kDa}$, corresponding to a 1:4 mix of S-70 to S-19. Results for the unmixed S-19 and S-70 are also included for reference. (c, d) Comparisons of the hole mobility for the mixed distribution samples (red, open symbols) and the single distribution samples of comparable molecular weight (blue, closed symbols) given in Table 1 as a function of annealing temperature. The samples shown here are (c) M-5 (corresponding to $\left.M_{\mathrm{w}}=37 \mathrm{kDa}\right)$ and $(\mathrm{d}) \mathrm{M}-50\left(M_{\mathrm{w}}=57 \mathrm{kDa}\right)$. Also depicted are the baselines for the single distribution samples S-19 and S-70 (black).

average number of crystals that each chain belongs to also increases, resulting in better connected crystals. We propose that the bulk, long-range mobility in semicrystalline polymers is limited below the short-range crystal mobilities by the availability of tie chains within the system. This, in turn, means that the noncrystalline sections of a semicrystalline morphology perform a useful function, although not all of the noncrystalline regions are useful tie chains.

As an example to show how the utility of the noncrystalline parts of the morphology can be improved, we engineered a P3HT sample with small molecular weight to include a proportion of longer chains to act as tie chains. We showed that adding long chains resulted in improved mobility which was comparable to a single-distribution sample of the same average molecular weight. The added chains were shown to have improved crystal connectivity, supporting the conclusion that tie chains are the main contributor to the molecular weight dependence of the mobility and simultaneously showing that a high polydispersity is not necessarily detrimental to charge transport within the active layer. These conclusions need not be specific to the test system of P3HT and may be generally true for other semicrystalline polymers.

\section{ASSOCIATED CONTENT}

\section{S Supporting Information}

The Supporting Information is available free of charge on the ACS Publications website at DOI: 10.1021/acs.jpcc.5b11511.

Parametrization of coarse-grained regioregular P3HT model, chain length distribution, potential energy and morphological evolution, fine graining methodology, Gaussian mapping of the density of states, and determination of the reorganization energy and transfer integrals. All underpinning data used in the investigations can be found at DOI: $10.15128 / 8 \mathrm{k} 71 \mathrm{nh} 08 \mathrm{w}$. (PDF)

\section{AUTHOR INFORMATION}

\section{Corresponding Author}

*E-mail: chris.groves@durham.ac.uk (C.G.).

\section{Notes}

The authors declare no competing financial interest.

\section{ACKNOWLEDGMENTS}

All simulations were performed on Durham University's High Performance Computing cluster Hamilton. M.L.J. has a scholarship funded by EPSRC doctoral training award. D.M.H. acknowledges computational resources provided by the NCI National Facility systems at the Australian National 
University through the National Computational Merit Allocation Scheme supported by the Australian Government.

\section{REFERENCES}

(1) McCullough, R. D.; Tristram-Nagle, S.; Williams, S. P.; Lowe, R. D.; Jayaraman, M. Self-Oriented Head-to-Tail Poly(3-Alkythiophenes): New Insights on Structure-Property Relationships in Conducting Polymers. J. Am. Chem. Soc. 1993, 115, 4910-4911.

(2) Crossland, E. J. W.; Tremel, K.; Fischer, F.; Rahimi, K.; Reiter, G.; Steiner, U.; Ludwigs, S. Anisotropic Charge Transport in Spherulitic Poly(3-hexylthiophene) Films. Adv. Mater. 2012, 24, 839-844.

(3) Krebs, F. C.; Tromholt, T.; Jørgensen, M. Upscaling of Polymer Solar Cell Fabrication Using Full Roll-to-Roll Processing. Nanoscale 2010, 2, 873-886.

(4) Arias, A. C.; MacKenzie, J. D.; McCulloch, I.; Rivnay, J.; Salleo, A. Materials and Applications for Large Area Electronics: Solution-Based Approaches. Chem. Rev. 2010, 110, 3-24.

(5) Tsumura, A.; Koezuka, H.; Ando, T. Macromolecular Electronic Device: Field-Effect Transistor with a Polythiophene Thin Film. Appl. Phys. Lett. 1986, 49, 1210-1212.

(6) Burroughes, J. H.; Bradley, D. D. C.; Brown, A. R.; Marks, R. N.; Mackay, K.; Friend, R. H.; Burns, P. L.; Holmes, A. B. Light-Emitting Diodes Based on Conjugated Polymers. Nature 1990, 347, 539-541.

(7) Friend, R. H.; Gymer, R. W.; Holmes, A. B.; Burroughes, J. H.; Marks, R. N.; Taliani, C.; Bradley, D. D. C.; Dos Santos, D. A.; Brédas, J. L.; Lögdlund, M.; Salaneck, W. R. Electroluminescence in Conjugated Polymers. Nature 1999, 397, 121-128.

(8) Sariciftci, N. S.; Smilowitz, L.; Heeger, A. J.; Wudl, F. Photoinduced Electron Transfer from a Conducting Polymer to Buckminsterfullerene. Science 1992, 258, 1474-1476.

(9) Abrusci, A.; Stranks, S. D.; Docampo, P.; Yip, H.-L.; Jen, A. K.-Y.; Snaith, H. J. High-Performance Perovskite-Polymer Hybrid Solar Cells via Electronic Coupling with Fullerene Monolayers. Nano Lett. 2013, 13, 3124-3128.

(10) Facchetti, A. Polymer Donor-Polymer Acceptor (All-Polymer) Solar Cells. Mater. Today 2013, 16, 123-132.

(11) Günes, S.; Neugebauer, H.; Sariciftci, N. S. Conjugated Polymer-Based Organic Solar Cells. Chem. Rev. 2007, 107, 13241338.

(12) Sirringhaus, H. 25th Anniversary Article: Organic Field-Effect Transistors: The Path Beyond Amorphous Silicon. Adv. Mater. 2014, 26, 1319-1335.

(13) Bronstein, H.; Chen, Z.; Ashraf, R. S.; Zhang, W.; Du, J.; Durrant, J. R.; Tuladhar, P. S.; Song, K.; Watkins, S. E.; Geerts, Y.; Wienk, M. M.; Janssen, R. A. J.; Anthopoulos, T.; Sirringhaus, H.; Heeney, M.; McCulloch, I. Thieno[3,2-b]thiophene-Diketopyrrolopyrrole-Containing Polymers for High-Performance Organic FieldEffect Transistors and Organic Photovoltaic Devices. J. Am. Chem. Soc. 2011, 133, 3272-3275.

(14) McCulloch, I.; Heeney, M.; Bailey, C.; Genevicius, K.; MacDonald, I.; Shkunov, M.; Sparrowe, D.; Tierney, S.; Wagner, R.; Zhang, W.; Chabinyc, M. L.; Kline, R. J.; McGehee, M. D.; Toney, M. F. Liquid-Crystalline Semiconducting Polymers with High ChargeCarrier Mobility. Nat. Mater. 2006, 5, 328-333.

(15) Tsao, H. N.; Cho, D. M.; Park, I.; Hansen, M. R.; Mavrinskiy, A.; Yoon, D. Y.; Graf, R.; Pisula, W.; Spiess, H. W.; Müllen, K. Ultrahigh Mobility in Polymer Field-Effect Transistors by Design. J. Am. Chem. Soc. 2011, 133, 2605-2612.

(16) Sirringhaus, H.; Tessler, N.; Friend, R. H. Integrated Optoelectronic Devices Based on Conjugated Polymers. Science 1998, 280, 1741-1744.

(17) Scharsich, C.; Lohwasser, R. H.; Sommer, M.; Asawapirom, U.; Scherf, U.; Thelakkat, M.; Neher, D.; Köhler, A. Control of Aggregate Formation in Poly(3- hexylthiophene) by Solvent, Molecular Weight, and Synthetic Method. J. Polym. Sci., Part B: Polym. Phys. 2012, 50, $442-453$.

(18) Li, G.; Shrotriya, V.; Huang, J.; Yao, Y.; Moriarty, T.; Emery, K.; Yang, Y. High-Efficiency Solution Processable Polymer Photovoltaic
Cells by Self-Organization of Polymer Blends. Nat. Mater. 2005, 4, 864-868.

(19) Noriega, R.; Rivnay, J.; Vandewal, K.; Koch, F. P. V.; Stingelin, N.; Smith, P.; Toney, M. F.; Salleo, A. A General Relationship Between Disorder, Aggregation and Charge Transport in Conjugated Polymers. Nat. Mater. 2013, 12, 1038-1044.

(20) Voigt, M. M.; Guite, A.; Chung, D.-Y.; Khan, R. U. A.; Campbell, A. J.; Bradley, D. D. C.; Meng, F.; Steinke, J. H. G.; Tierney, S.; McCulloch, I.; Penxten, H.; Lutsen, L.; Douheret, O.; Manca, J.; Brokmann, U.; Sönnichsen, K.; Hülsenberg, D.; Bock, W.; Barron, C.; Blanckaert, N.; Springer, S.; Grupp, J.; Mosley, A. Polymer Field-Effect Transistors Fabricated by the Sequential Gravure Printing of Polythiophene, Two Insulator Layers and a Metal Ink Gate. Adv. Funct. Mater. 2010, 20, 239-246.

(21) Fabiano, S.; Chen, Z.; Vahedi, S.; Facchetti, A.; Pignataro, B.; Loi, M. A. Role of Photoactive Layer Morphology in High Fill Factor All-Polymer Bulk Heterojunction Solar Cells. J. Mater. Chem. 2011, 21, 5891-5896.

(22) Sirringhaus, H.; Brown, P. J.; Friend, R. H.; Nielsen, M. M.; Bechgaard, K.; Langeveld-Voss, B. M. W.; Spiering, A. J. H.; Janssen, R A. J.; Meijer, E. W.; Herwig, P.; de Leeuw, D. M. Two-Dimensional Charge Transport in Self-Organised, High-Mobility Conjugated Polymers. Nature 1999, 401, 685-688.

(23) Kim, Y.; Cook, S.; Tuladhar, S. M.; Choulis, S. A.; Nelson, J.; Durrant, J. R.; Bradley, D. D. C.; Giles, M.; McCulloch, I.; Ha, C.-S.; Ree, M. A Strong Regioregularity Effect in Self-Organising Conjugated Polymer Films and High-Efficiency Polythiophene: Fullerene Solar Cells. Nat. Mater. 2006, 5, 197-203.

(24) Surin, M.; Leclère, P.; Lazzaroni, R.; Yuen, J. D.; Wang, G.; Moses, D.; Heeger, A. J.; Cho, S.; Lee, K. Relationship Between the Microscopic Morphology and the Charge Transport Properties in Poly(3-hexylthiophene) Field-Effect Transistors. J. Appl. Phys. 2006, $100,033712$.

(25) Kim, D. H.; Park, Y. D.; Jang, Y.; Kim, S.; Cho, K. Solvent Vapor-Induced Nanowire Formation in Poly(3-hexylthiophene) Thin Films. Macromol. Rapid Commun. 2005, 26, 834-839.

(26) Pandey, S. S.; Takashima, W.; Nagamatsu, S.; Endo, T.; Rikukawa, M.; Kaneto, K. Regioregularity vs Regiorandomness: Effect on Photocarrier Transport in Poly(3-hexylthiophene). Jpn. J. Appl. Phys. 2000, 39, L94-L97.

(27) Mauer, R.; Kastler, M.; Laquai, F. The Impact of Polymer Regioregularity on Charge Transport and Efficiency of P3HT:PCBM Photovoltaic Devices. Adv. Funct. Mater. 2010, 20, 2085-2092.

(28) Zen, A.; Pflaum, J.; Hirschmann, S.; Zhuang, W.; Jaiser, F.; Asawapriom, U.; Rabe, J. P.; Scherf, U.; Neher, D. Effect of Molecular Weight and Annealing of Poly(3-hexylthiophene)s on the Performance of Organic Field-Effect Transistors. Adv. Funct. Mater. 2004, 14, 757764.

(29) Wang, H.; Xu, Y.; Yu, X.; Xing, R.; Liu, J.; Han, Y. Structure and Morphology Control in Thin Films of Conjugated Polymers for an Improved Charge Transport. Polymers 2013, 5, 1272-1324.

(30) Kohn, P.; Huettner, S.; Komber, H.; Senkovskyy, V.; Tkachov, R.; Kiriy, A.; Friend, R. H.; Steiner, U.; Huck, W. T. S.; Sommer, J.-U.; Sommer, M. On the Role of Single REgiodefects and Polydispersity in Regioregular Poly(3-hexylthiophene): Defect Distribution, Synthesis of Defect-Free Chains, and a Simple Model for the Determination of Crystallinity. J. Am. Chem. Soc. 2012, 134, 4790-4805.

(31) Zen, A.; Saphiannikova, M.; Neher, D.; Grenzer, J.; Grigorian, S.; Pietsch, U.; Asawapirom, U.; Janietz, S.; Scherf, U.; Lieberwirth, I.; Wegner, G. Effect of MolecularWeight on the Structure and Crystallinity of Poly(3-hexylthiophene). Macromolecules 2006, 39, $2162-2171$

(32) Schilinsky, P.; Asawapirom, U.; Scherf, U.; Biele, M.; Brabec, C. J. In uence of the Molecular Weight of Poly(3-hexylthiophene) on the Performance of Bulk Heterojunction Solar Cells. Chem. Mater. 2005, $17,2175-2180$.

(33) Ballantyne, A. M.; Chen, L.; Dane, J.; Hammant, T.; Braun, F. M.; Heeney, M.; Duffy, W.; McCulloch, I.; Bradley, D. D. C.; Nelson, J. The Effect of Poly(3-hexylthiophene) Molecular Weight on Charge 
Transport and the Performance of Polymer: Fullerene Solar Cells. Adv. Funct. Mater. 2008, 18, 2373-2380.

(34) Cheung, D. L.; McMahon, D. P.; Troisi, A. Computational Study of the Structure and Charge-Transfer Parameters in LowMolecular-Mass P3HT. J. Phys. Chem. B 2009, 113, 9393-9401.

(35) Koch, F. P. V.; Rivnay, J.; Foster, S.; Müller, C.; Downing, J. M.; Buchaca-Domingo, E.; Westacott, P.; Yu, L.; Yuan, M.; Baklar, M.; Fei, Z.; Luscombe, C.; McLachlan, M. A.; Heeney, M.; Rumbles, R.; Silva, C.; Salleo, A.; Nelson, J.; Smith, P.; Stingelin, N. The Impact of Molecular Weight on Microstructure and Charge Transport in Semicrystalline Polymer Semiconductors - poly(3-hexylthiophene), a Model Study. Prog. Polym. Sci. 2013, 38, 1978-1989.

(36) Brinkmann, M.; Rannou, P. Molecular Weight Dependence of Chain Packing and Semicrystalline Structure in Oriented Films of Regioregular Poly(3-hexylthiophene) Revealed by High-Resolution Transmission Electron Microscopy. Macromolecules 2009, 42, 11251130.

(37) Lim, J. A.; Liu, F.; Ferdous, S.; Muthukumar, M.; Briseno, A. L. Polymer Semiconductor Crystals. Mater. Today 2010, 13, 14-24.

(38) Peumans, P.; Uchida, S.; Forrest, S. R. Efficient Bulk Heterojunction Photovoltaic Cells Using Small-Molecular-Weight Organic Thin Films. Nature 2003, 425, 158-162.

(39) Henderson, I. C.; Clarke, N. On Modelling Surface Directed Spinodal Decomposition. Macromol. Theory Simul. 2005, 14, 435-443. (40) Do, K.; Huang, D. M.; Faller, R.; Moulé, A. J. A Comparative MD Study of the Local Structure of Polymer Semiconductors P3HT and PBTTT. Phys. Chem. Chem. Phys. 2010, 12, 14735-14739.

(41) Carrillo, J.-M. Y.; Kumar, R.; Goswami, M.; Sumpter, B. G.; Brown, W. M. New Insights into the Dynamics and Morphology of P3HT:PCBM Active Layers in Bulk Heterojunctions. Phys. Chem. Chem. Phys. 2013, 15, 17873-17882.

(42) To, T. T.; Adams, S. Modelling of P3HT:PCBM Interface Using Coarse-Grained Force-field Derived from Accurate Atomistic Forcefield. Phys. Chem. Chem. Phys. 2014, 16, 4653-4663.

(43) Huang, D. M.; Faller, R.; Do, K.; Moulé, A. J. Coarse-Grained Computer Simulations of Polymer/Fullerene Bulk Heterojunctions for Organic Photovoltaic Applications. J. Chem. Theory Comput. 2010, 6, $526-537$.

(44) Lee, C.-K.; Pao, C.-W.; Chu, C.-W. Multiscale Molecular Simulations of the Nanoscale Morphologies of P3HT:PCBM Blends for Bulk Heterojunction Organic Photovoltaic Cells. Energy Environ. Sci. 2011, 4, 4124-4132.

(45) Schwarz, K. N.; Kee, T. W.; Huang, D. M. Coarse-Grained Simulations of the Solution- Phase Self-Assembly of poly(3hexylthiophene) Nanostructures. Nanoscale 2013, 5, 2017-2027.

(46) Huang, D. M. Computational Study of P3HT/C60-Fullerene Miscibility. Aust. J. Chem. 2014, 67, 585-591.

(47) Marsh, H. S.; Jankowski, E.; Jayaraman, A. Controlling the Morphology of Model Conjugated Thiophene Oligomers through Alkyl Side Chain Length, Placement, and Interactions. Macromolecules 2014, 47, 2736-2747.

(48) Jankowski, E.; Marsh, H. S.; Jayaraman, A. Computationally Linking Molecular Features of Conjugated Polymers and Fullerene Derivatives to Bulk Heterojunction Morphology. Macromolecules 2013, 46, 5775-5785.

(49) Schrader, M.; Fitzner, R.; Hein, M.; Elschner, C.; Baumeier, B.; Leo, K.; Riede, M.; Bäuerle, P.; Andrienko, D. Comparitive Study of Microscopic Charge Dynamics in Crystalline Acceptor-Substituted Oligothiophenes. J. Am. Chem. Soc. 2012, 134, 6052-6056.

(50) Poelking, C.; Andrienko, D. Effect of Polymorphism, Regioregularity and Paracrystallinity on Charge Transport in Poly(3hexylthiophene) [P3HT] Nanofibers. Macromolecules 2013, 46, 89418956.

(51) Tapping, P. C.; Clafton, S. N.; Schwarz, K. N.; Kee, T. W.; Huang, D. M. Molecular-Level Details of Morphology-Dependent Exciton Migration in Poly(3-hexylthiophene) Nanostructures. J. Phys. Chem. C 2015, 119, 7047-7059.

(52) Flory, P. J. Molecular Size Distribution in Ethylene Oxide Polymers. J. Am. Chem. Soc. 1940, 62, 1561-1565.
(53) Prosa, T. J.; Winokur, M. J.; Moulton, J.; Smith, P.; Heeger, A. J. $\mathrm{X}$-ray Structural Studies of poly(3-alkylthiophenes): an Example of an Inverse Comb. Macromolecules 1992, 25, 4364-4372.

(54) Shinoda, W.; Shiga, M.; Mikami, M. Rapid estimation of elastic constants by molecular dynamics simulation under constant stress. Phys. Rev. B: Condens. Matter Mater. Phys. 2004, 69, 134103.

(55) Plimpton, S. J. Fast parallel algorithms for short-range molecular dynamics. J. Comput. Phys. 1995, 117, 1-19.

(56) McMahon, D. P.; Cheung, D. L.; Goris, L.; Dacuña, J.; Salleo, A.; Troisi, A. Relation between Microstructure and Charge Transport in Polymers of Different Regioregularity. J. Phys. Chem. C 2011, 115, 19386-19393.

(57) Wu, Z.; Petzold, A.; Henze, T.; Thurn-Albrecht, T.; Lohwasser, R. H.; Sommer, M.; Thelakkat, M. Temperature and Molecular Weight Dependent Hierarchical Equilibrium Structures in Semiconducting Poly(3-hexylthiophene). Macromolecules 2010, 43, 4646-4653.

(58) Hindeleh, A. M.; Hosemann, R. Paracrystals Representing the Physical State of Matter. J. Phys. C: Solid State Phys. 1988, 21, 41554170.

(59) Darling, S. B.; Sternberg, M. Importance of Side Chains and Backbone Length in Defect Modeling of Poly(3-alkylthiophenes). J. Phys. Chem. B 2009, 113, 6215-6218.

(60) Babel, A.; Jenekhe, S. A. Alkyl Chain Length Dependence of the Field-Effect Carrier Mobility in Regioregular poly(3-alkylthiophene)s. Synth. Met. 2005, 148, 169-173.

(61) Tummala, N. R.; Risko, C.; Bruner, C.; Dauskardt, R. H.; Brédas, J.-L. Entanglements in P3HT and Their In uence on ThinFilm Mechanical Properties: Insights from Molecular Dynamics Simulations. J. Polym. Sci., Part B: Polym. Phys. 2015, 53, 934-942.

(62) Murthy, D. H. K.; Gao, M.; Vermeulen, M. J. W.; Siebbeles, L. D. A.; Savenije, T. J. Mechanism of Mobile Charge Carrier Generation in Blends of Conjugated Polymers and Fullerenes: Significance of Charge Delocalisation and Excess Free Energy. J. Phys. Chem. C 2012, 116, 9214-9220.

(63) Vukmirovic, N.; Wang, L. W. Electronic Structure of Disordered Conjugated Polymers: Polythiophenes. J. Phys. Chem. B 2009, 113, 409-415.

(64) Ridley, J.; Zerner, M. An Intermediate Neglect of Differential Overlap Technique for Spectroscopy: Pyrrole and the Azines. Theoret. Chim. Acta 1973, 32, 111-134.

(65) Neese, F. The ORCA Program System. WIREs Comput. Mol. Sci. 2012, 2, 73-78.

(66) Mozer, A. J.; Sariciftci, N. S. Negative Electric Field Dependence of Charge Carrier Drift Mobility in Conjugated, Semiconducting Polymers. Chem. Phys. Lett. 2004, 389, 438-442.

(67) Koopmans, T. Über die Zuordnung von Wellenfunktionen und Eigenwerten zu den Einzelnen Elektronen Eines Atoms. Physica 1934, $1,104-113$.

(68) Coropceanu, V.; Cornil, J.; da Silva Filho, D. A.; Olivier, Y.; Silbey, R.; Brédas, J.-L. Charge Transport in Organic Semiconductors. Chem. Rev. 2007, 107, 926-952.

(69) Lan, Y.-K.; Huang, C.-I. A Theoretical Study of the Charge Transfer Behaviour of the Highly Regioregular Poly-3-hexylthiophene in the Ordered State. J. Phys. Chem. B 2008, 112, 14857-14862.

(70) Chen, H.-Y.; Chao, I. Effect of Per uorination on the ChargeTransport Properties of Organic Semiconductors: Density Functional Theory Study of Per uorinated Pentacene and Sexithiophene. Chem. Phys. Lett. 2005, 401, 539-545.

(71) Blancafort, L.; Voityuk, A. A. CASSCF/CAS-PT2 Study of Hole Transfer in Stacked DNA Nucleobases. J. Phys. Chem. A 2006, 110, 6426-6432.

(72) Marcus, R. A. Chemical and Electrochemical Electron-Transfer Theory. Annu. Rev. Phys. Chem. 1964, 15, 155-196.

(73) Johansson, E.; Larsson, S. Electronic Structure and Mechanism for Conductivity in Thiophene Oligomers and Regioregular Polymer. Synth. Met. 2004, 144, 183-191.

(74) Hartenstein, B.; Bassler, H. Transport Energy for Hopping in a Gaussian Density-of-States Distribution. J. Non-Cryst. Solids 1995, 190, $112-116$. 
(75) Nelson, J.; Kwiatkowski, J. J.; Kirkpatrick, J.; Frost, J. M. Modeling Charge Transport in Organic Photovoltaic Materials. Acc. Chem. Res. 2009, 42, 1768-1778.

(76) Vehoff, T.; Baumeier, B.; Troisis, A.; Andrienko, D. Charge Transport in Organic Crystals: Role of Disorder and Topological Connectivity. J. Am. Chem. Soc. 2010, 132, 11702-11708.

(77) Cho, S.; Lee, K.; Yuen, J.; Wang, G.; Moses, D.; Heeger, A. J.; Surin, M.; Lazzaroni, R. Thermal Annealing-Induced Enhancement of the Field-Effect Mobility of Regioregular Poly(3-hexylthiophene) Films. J. Appl. Phys. 2006, 100, 114503.

(78) Mihailetchi, V. D.; Xie, H. X.; de Boer, B.; Koster, L. J. A.; Blom, P. W. M. Charge Transport and Photocurrent Generation in Poly(3hexylthiophene):Methanofullerene Bulk-Heterojunction Solar Cells. Adv. Funct. Mater. 2006, 16, 699-708.

(79) Kline, R. J.; McGehee, M. D.; Kadnikova, E. N.; Liu, J.; Fréchet, J. M. J. Controlling the Field-Effect Mobility of Regioregular Polythiophene by Changing the Molecular Weight. Adv. Mater. 2003, 15, 1519-1522.

(80) Verilhac, J.-M.; Pokrop, R.; LeBlevennec, G.; Kulszewicz-Bajer, I.; Buga, K.; Zagorska, M.; Sadki, S.; Pron, A. Molecular Weight Dependent Charge Carrier Mobility in Poly $\left(3,3^{\prime \prime}\right.$-dioctyl-2,2':5',2"terthiophene). J. Phys. Chem. B 2006, 110, 13305-13309.

(81) Chang, J.-F.; Clark, J.; Zhao, N.; Sirringhaus, H.; Breiby, D. W.; Andreasen, J. W.; Nielsen, M. M.; Giles, M.; Heeney, M.; McCulloch, I. Molecular-Weight Dependence of Interchain Polaron Delocalization and Exciton Bandwidth in High-Mobility Conjugated Polymers. Phys. Rev. B: Condens. Matter Mater. Phys. 2006, 74, 115318.

(82) Hindeleh, A. M.; Hosemann, R. A review Microparacrystals: The Intermediate Stage Between Crystalline and Amorphous. J. Mater. Sci. 1991, 26, 5127-5133.

(83) Rivnay, J.; Noriega, R.; Kline, R. J.; Salleo, A.; Toney, M. F. Quantitative Analysis of Lattice Disorder and Crystallite Size in Organic Semiconductor Thin Films. Phys. Rev. B: Condens. Matter Mater. Phys. 2011, 84, 045203.

(84) Poelking, C.; Cho, E.; Malafeev, A.; Ivanov, V.; Kremer, K.; Risko, C.; Brédas, J.-L.; Andrienko, D. Characterization of ChargeCarrier Transport in Semicrystalline Polymers: Electronic Couplings, Site Energies and Charge-Carrier Dynamics in Poly(bithiophene-altthienothiophene) [PBTTT]. J. Phys. Chem. C 2013, 117, 1633-1640.

(85) Lilliu, S.; Agostinelli, T.; Pires, E.; Hampton, M.; Nelson, J.; Macdonald, J. E. Dynamic of Crystallization and Disorder During Annealing of P3HT/PCBM Bulk Heterojunctions. Macromolecules 2011, 44, 2725-2734.

(86) Reid, O. G.; Nekuda Malik, J. A.; Latini, G.; Dayal, S.; Kopidakis, N.; Silva, C.; Stingelin, N.; Rumbles, G. The Influence of Solid-State Microstructure on the Origin and Yield of Long-Lived Photogenerated Charge in Neat Semiconducting Polymers. J. Polym. Sci., Part B: Polym. Phys. 2012, 50, 27-37.

(87) Mollinger, S. A.; Krajina, B. A.; Noriega, R.; Salleo, A.; Spakowitz, A. J. Percolation, Tie-Molecules and the Microstructural Determinants of Charge Transport in Semicrystalline Conjugated Polymers. ACS Macro Lett. 2015, 4, 708-712. 